\title{
Seasonal Effects on Heavy Metal Concentration in Decomposed Solid Waste of DNCC and DSCC Landfill Sites
}

\author{
M. A. Hoque ${ }^{1}$, M. Aminul Haque ${ }^{1,2,{ }^{*}}$, M. S. A. Mondal ${ }^{3}$ \\ ${ }^{1}$ Department of Civil and Environmental Engineering, Shahjalal University of Science and Technology, Sylhet, Bangladesh \\ ${ }^{2}$ Department of Civil Engineering, Leading University, Sylhet, Bangladesh \\ ${ }^{3}$ Japan International Cooperation Agency Expert Team, Dhaka North and South City Corporation, Bangladesh \\ * Corresponding Author:: eman.cee2008@gmail.com
}

Copyright (C) 2014 Horizon Research Publishing All rights reserved.

\begin{abstract}
To assess the seasonal variation of heavy metals (such as $\mathrm{Fe}, \mathrm{Cu}, \mathrm{Cd}$, Ni and $\mathrm{Cr}$ ) concentration in decomposed waste, converted soil and leachate the samples were collected from Matuail and Aminbazar landfill sites of Dhaka North City Corporation (DNCC) and Dhaka South City Corporation (DSCC) respectively and were analyzed for summer (dry season) and monsoon (wet season) periods. Significant variations in the concentrations of heavy metals for two seasons were noted at both landfill sites. This study reveals that the heavy metal concentrations in the decomposed waste and converted soil are higher in the summer as compared to that in the monsoon. In the case of leachate samples, lower concentrations of heavy metals were observed during the summer season whereas the average concentrations of $\mathrm{Fe}, \mathrm{Cu}$, and $\mathrm{Ni}$ during the monsoon were found as high as $25.3 \mathrm{mg} / 1,1.5 \mathrm{mg} / \mathrm{l}, 4.46 \mathrm{mg} / \mathrm{l}$ (at Matuail landfill site) and $14.71 \mathrm{mg} / \mathrm{l}, 1.14 \mathrm{mg} / \mathrm{l}, 2.32 \mathrm{mg} / \mathrm{l}$ (at Aminbazar landfill site) respectively, exceeding Bangladesh standards for inland surface water. The outcome of this study gives the leaching behavior of heavy metals with seasonal variations and indicates the necessity of solid waste stabilization for heavy metal immobilization within the solidified matrix bond and re-use of solidified/stabilized products for sustainable solid waste management.
\end{abstract}

Keywords Decomposed Solid Waste, Landfill Site, Heavy metal, Leachate, Monsoon and Summer

\section{Introduction}

In a mega city like Dhaka, large volume of solid wastes is a big concern because of constituting enormous public health and environmental problems. The authorities of DNCC and DSCC are facing incredible stress to maintain the solid waste disposal services due to the fast increasing of population.
The solid waste collection rate of DNCC and DSCC is estimated about $44 \%$ of generated volume [1]. The collected solid wastes from both city corporation areas are disposed at Matuail and Aminbazar sanitary landfill sites without any physical segregation of hazardous materials. Leachate of landfill decomposed solid wastes and converted soils conveys heavy metals such as $\mathrm{Fe}, \mathrm{Cu}, \mathrm{Cd}, \mathrm{Ni}, \mathrm{Cr}$ etc. that may get into surface water body or percolate groundwater causing potential water contamination [2], [3]. Such contamination of water resources may possess substantial risk to the local natural environment at landfill sites. Heavy metal percolates the soil layer of agricultural land near landfill sites which may transfer to the food chain through the bio-accumulation of plants [4]. Similarly, the toxic elements may lead to enter the body system through food, air and water over a period of time [5].

During the monsoon season, there is a greater chance of heavy metal movement than summer due to the rain water flow mechanisms from the landfill decomposed wastes and converted soils to the near environment at landfill sites. Since the landfill sites are faced to a wide range of seasonal variations, the leaching behavior of heavy metals particularly in monsoon (wet season) and summer (dry season) periods should be examined to get better understanding the possibility of heavy metal entrance in toxic level to the environment.

In this paper, it is therefore aimed to investigate the presence of heavy metals in decomposed solid waste, converted soil and leachate samples that were collected from Dhaka City Corporations landfill sites along with the assessment of heavy metal release pattern with the seasonal variation (summer and monsoon). In this research, Matuail and Aminbazar sanitary landfill sites have been selected as the study area.

\section{Materials and Methods}




\subsection{Sampling Procedure}

In this current research, three different types of samples such as a) decomposed solid waste (DSW) from waste disposal area, b) converted soil (CS) (soil used for vegetation) and c) leachate from leachate pond were collected from Matuail and Aminbazar landfill sites to determine the heavy metals concentration. Figure 1 and 2 represent the location of sampling points of DSW samples at Matuail and Aminbazar landfill sites respectively. DSW sampling points SP-01, SP-02, SP-03, SP-04, and SP-05 were selected based on the age of decomposition of solid waste having 7, 5, 4, 3, and 1 year respectively [3]. At each location, samples were collected at $0.5 \mathrm{~m}$ depth [6].

Five different vegetate locations (not shown in Figure) have been chosen during the sampling of converted soil. Leachate samples were collected from untreated and treated (treated by only aeration) leachate pond of both landfill sites.

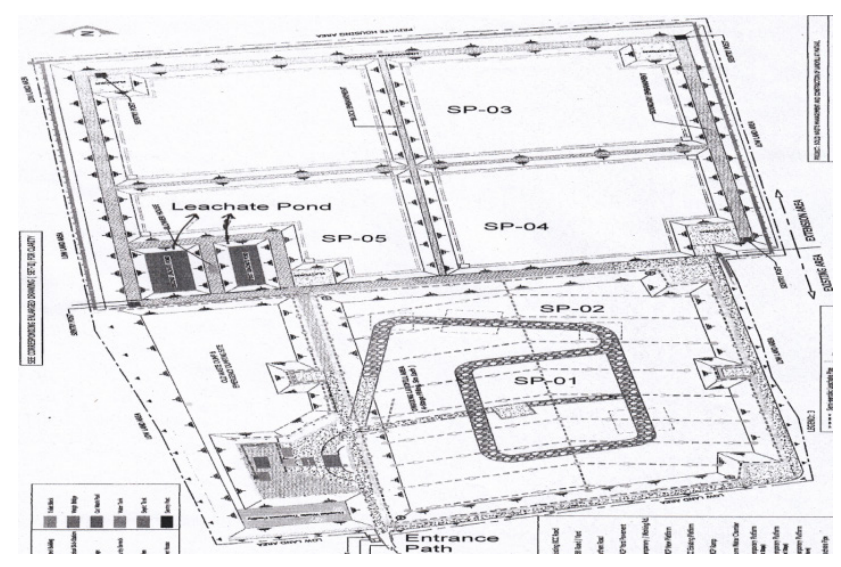

Figure 1. Location of DSW sampling points of at Matuail landfill site

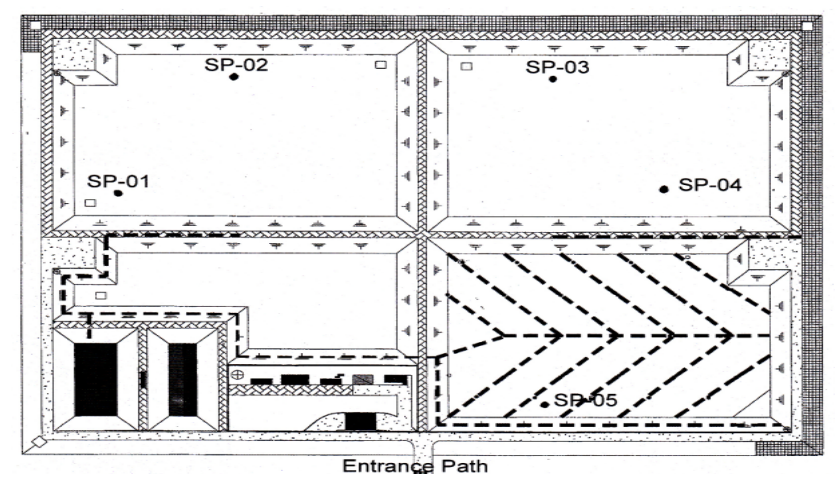

Figure 2. Location of DSW sampling points at Aminbazar landfill site

\subsection{Analytical Method}

Decomposed solid waste and converted soil samples were air-dried as the requirements of laboratory experiment. Both samples were digested for chemical properties analysis using Aqua-Regia digestion method. Five parameters such as $\mathrm{Fe}, \mathrm{Cu}, \mathrm{Cd}, \mathrm{Ni}$ and $\mathrm{Cr}$ were chosen for the investigation of toxicity level in solid waste, converted soil and leachate samples. The concentration of $\mathrm{Fe}, \mathrm{Cu}$ and
Cd were analyzed using flame emission atomic absorption spectrophotometer (AAS) (Spectra AA Varian), whereas $\mathrm{Cr}$ and $\mathrm{Ni}$ were estimated using Hach DR/4000 Spectrophotometer (Method: 8023 and 8037). Heavy metals concentration from leachate samples were also analyzed using AAS and Hach DR/4000 Spectrophotometer.

\section{Results and Discussions}

The variation in concentration of heavy metals such as Fe, $\mathrm{Cu}, \mathrm{Cd}, \mathrm{Ni}$ and $\mathrm{Cr}$ in decomposed solid waste and converted soil samples during the summer and monsoon seasons are shown in Figure 3 to Figure 7. In each case, higher concentration of heavy metal is noted during the dry season (summer) as compared to that observed during the wet season (monsoon). In addition, the presence of heavy metals was found lesser in converted soil as compared to that in the decomposed waste indicating the greater chance of the toxic metals to release from solid waste to leachate (Figure 3 to Figure 7). In summer, Fe was the highest concentration about $14564 \mathrm{mg} / \mathrm{kg}$ and $9830 \mathrm{mg} / \mathrm{kg}$ in decomposed solid waste at Matuail and Aminbazar landfill sites respectively.

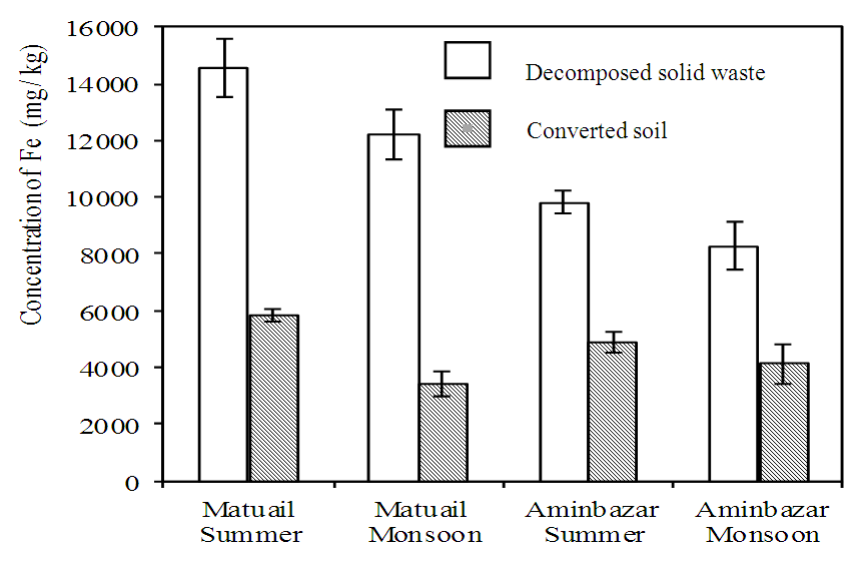

Figure 3. Concentration of Fe in DSW and CS samples

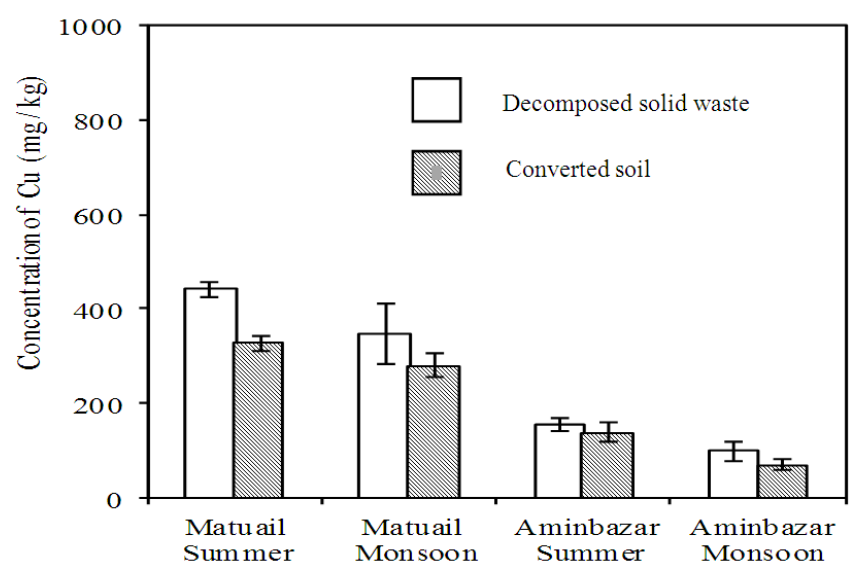

Figure 4. Concentration of $\mathrm{Cu}$ in DSW and CS samples

Similar result was observed by Mamtaz and Chowdhury (2006) [6] a high concentration of Fe $(9600 \mathrm{mg} / \mathrm{kg})$ in 
decomposed solid waste. Moreover, Oluyemi et al. (2008) [7] found $\mathrm{Fe}$ concentration about $4130.02 \mathrm{mg} / \mathrm{kg}$ in landfill site. $\mathrm{Cu}$ was found greater concentration (Figure 4) for both decomposed waste and converted soli such as $441.5 \mathrm{mg} / \mathrm{kg}$ and $155.5 \mathrm{mg} / \mathrm{kg}, 327.6 \mathrm{mg} / \mathrm{kg}$ and $138.0 \mathrm{mg} / \mathrm{kg}$ respectively in summer than monsoon at both landfill sites.

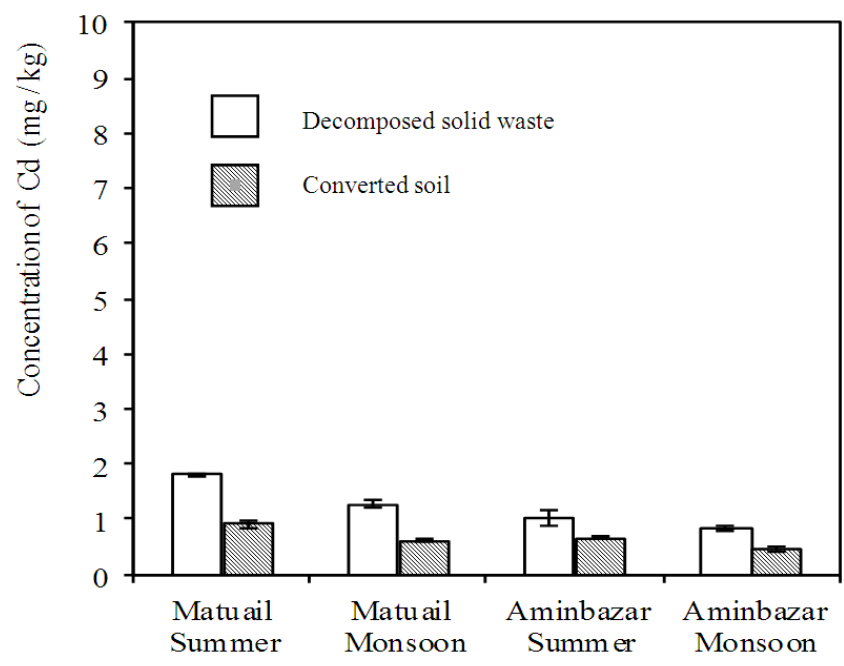

Figure 5. Concentration of Cd in DSW and CS samples

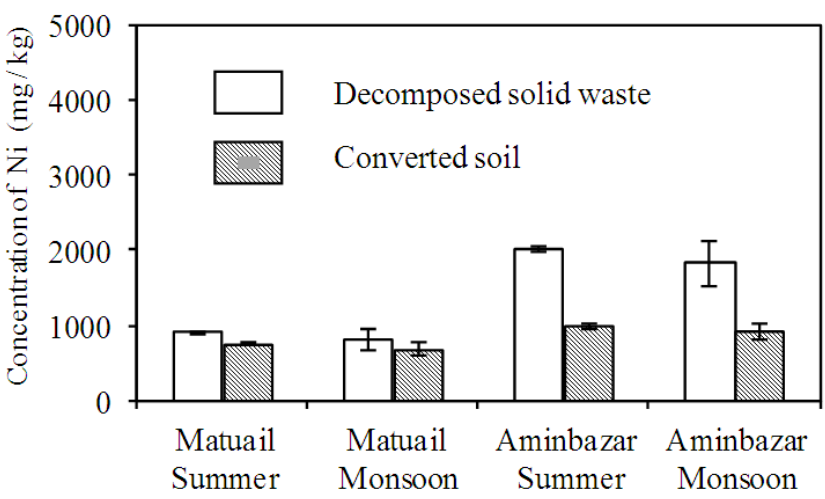

Figure 6. Concentration of Ni in DSW and CS samples

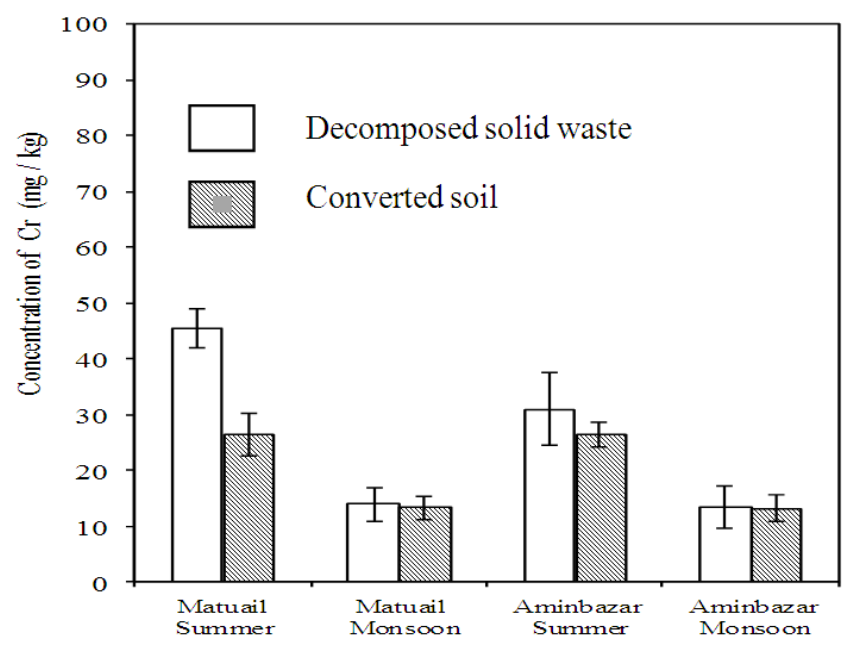

Figure 7. Concentration of Cr in DSW and CS samples
The concentration of $\mathrm{Cd}$ in the decomposed waste and converted soil was found to vary from $1.02-1.8 \mathrm{mg} / \mathrm{kg}$ and $0.67-0.92 \mathrm{mg} / \mathrm{kg}$ in summer and $0.83-1.27 \mathrm{mg} . \mathrm{kg}$ and $0.47-0.61 \mathrm{mg} / \mathrm{kg}$ in monsoon season respectively. Mamtaz and Chowdhury (2006) [6] and Adjia et al. (2008) [8] observed the concentration of $\mathrm{Cd}$ to be $0.8 \mathrm{mg} / \mathrm{kg}$ and 0.48 $\mathrm{mg} / \mathrm{kg}$ in decomposed solid waste respectively. In this current study, the concentration of $\mathrm{Ni}$ during both the summer and monsoon season was found to be significant (Figure 6) as compared to the observations of Mamtaz and Chowdhury (2006) [6] and Adjia et al. (2008) [8].

Table 1 shows the concentration of heavy metals in leachate samples collected from the untreated pond at Matuail and Aminbazar landfill sites for both the summer and monsoon seasons. Though the concentration of $\mathrm{Cd}$ and $\mathrm{Cr}$ was found to be safety limit according to the Bangladesh Environmental Conservation Rules, BECR (1997) [9], the average concentration of $\mathrm{Fe}, \mathrm{Cu}$ and $\mathrm{Ni}$ in the leachate samples collected from the untreated and treated leachate ponds are not safe for disposal to the environment without proper treatment since they exceed the Bangladesh standards (Figure 8, 9 \&10) and may cause severe surface and ground water pollution around the both landfill sites. Disposal of leachate in the inland surface water body from the landfill sites without proper treatment may lead to the source of contamination in the ecosystems of river, canal, stream etc.

Table 1. Concentration of heavy metals in landfill leachate (untreated)

\begin{tabular}{|c|c|c|c|c|c|}
\hline \multirow{2}{*}{$\begin{array}{c}\text { Heavy } \\
\text { Metal }\end{array}$} & \multicolumn{2}{|c|}{$\begin{array}{c}\text { Matuail } \\
\text { landfill site }\end{array}$} & \multicolumn{2}{c|}{$\begin{array}{c}\text { Aminbazar } \\
\text { landfill site }\end{array}$} & \multirow{2}{*}{$\begin{array}{c}\text { BECR } \\
1997\end{array}$} \\
\cline { 2 - 5 } & Summer & Monsoon & Summer & Monsoon & \\
\hline $\mathrm{Fe}$ & $17.2 \pm 2.1$ & $25.3 \pm 1.75$ & $10.2 \pm 1.02$ & $14.71 \pm 1.20$ & 2.0 \\
\hline $\mathrm{Cu}$ & $1.02 \pm 0.08$ & $1.5 \pm 0.05$ & $0.93 \pm 0.08$ & $1.14 \pm 0.02$ & 0.5 \\
\hline $\mathrm{Ni}$ & $3.18 \pm 0.28$ & $4.46 \pm 0.23$ & $1.83 \pm 0.07$ & $2.32 \pm 0.15$ & 1.0 \\
\hline $\mathrm{Cr}$ & $0.23 \pm 0.02$ & $0.36 \pm 0.02$ & $0.12 \pm 0.02$ & $0.18 \pm 0.01$ & 0.5 \\
\hline $\mathrm{Cd}$ & $0.13 \pm 0.01$ & $0.20 \pm 0.02$ & $0.19 \pm 0.02$ & $0.30 \pm 0.06$ & 0.5 \\
\hline
\end{tabular}

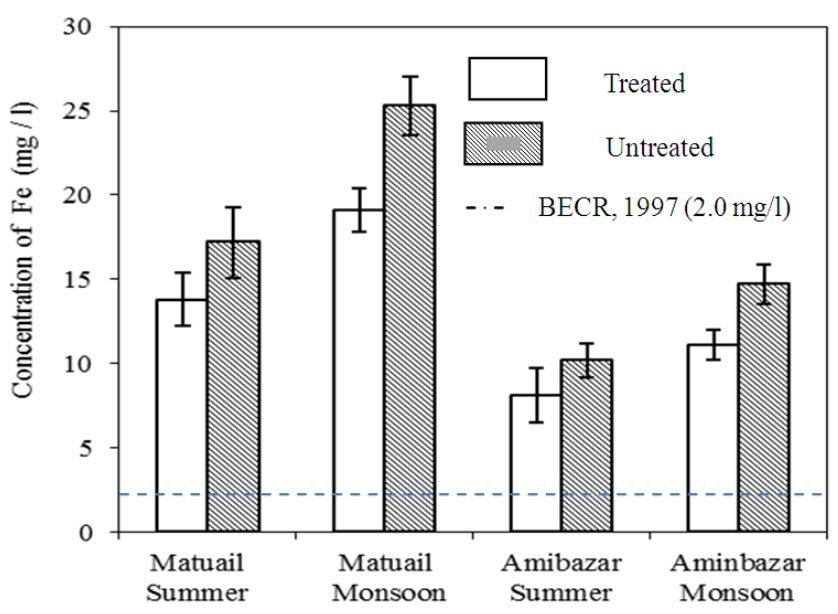

Figure 8. Concentration of $\mathrm{Fe}$ in landfill leachate samples 


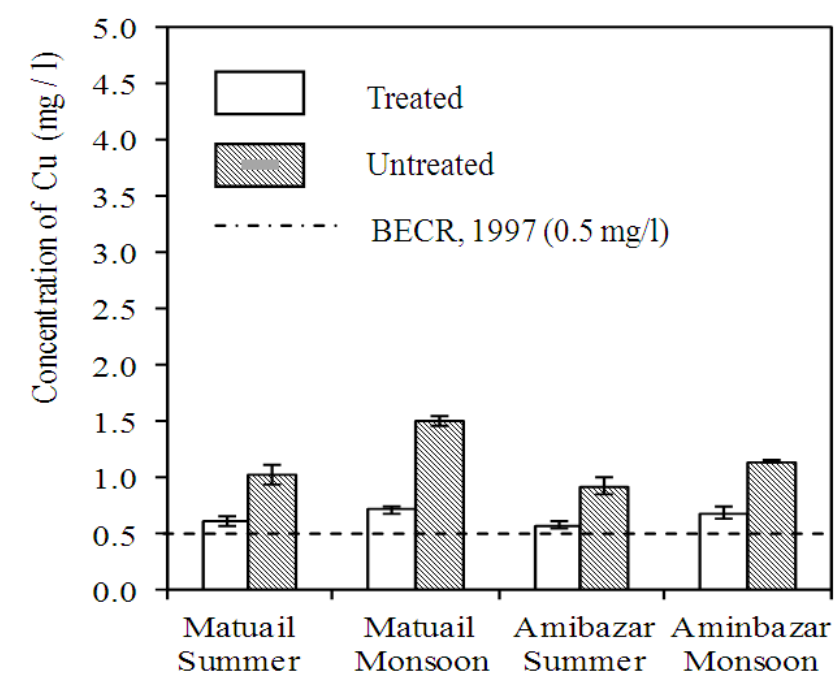

Figure 9. Concentration of $\mathrm{Cu}$ in landfill leachate samples

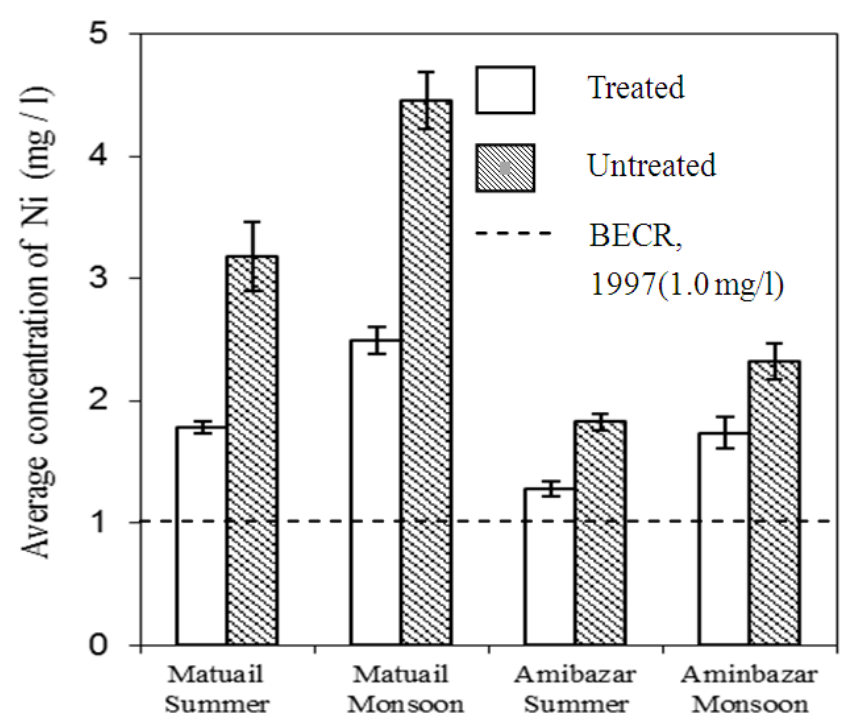

Figure 10. Concentration of $\mathrm{Ni}$ in landfill leachate samples

In this research, a specific pattern of the change of heavy metal concentration in the decomposed waste, converted soil, and leachate samples has been observed with seasonal variation. In monsoon season, the metal concentrations in both the decomposed waste and converted soil of two selected landfill sites are lesser as compared to that in the dry season, whereas a significant increase of heavy metals has been found in the leachate samples during the wet season indicating the release of heavy metals from solid to water phase due to the effect of rain water runoff and percolation [5].

There might be a great chance to wash away the heavy metals to the nearby low land and water body such as pond, irrigated land, lake, river, stream etc. through leaching. In addition, the entrance of toxic chemicals to the food chain may prolong adverse impact on human and livestock [10]. Moreover, surface and groundwater contamination may take place due to leaching of heavy metals unless proper lining (i.e. geotextile) that is hardly exercised at solid waste landfill sites in Bangladesh. So, landfill at the landfill site should be operated to a standard, which protects human health and the environment [11].

\section{Conclusion}

In this current study, the decomposed solid waste, converted soil and leachate samples were collected from the Matuail and Aminbazar landfill sites and analyzed for heavy metals concentration for summer and monsoon seasons to investigate the seasonal effects on leaching behavior. This study reveals that the heavy metal concentration reduces in two solid samples (decomposed solid waste and converted soil) and increases in the leachate during the monsoon season. This confirms the entrance of toxic metals from solid waste and converted soil to liquid phase. Though the leachate in both the Matuail and Aminbazar landfill sites are treated through aeration pond before the final disposal to the environment, the concentration of heavy metals particularly $\mathrm{Fe}, \mathrm{Cu}$ and $\mathrm{Ni}$ are found to remain beyond the Bangladesh standards. As a consequence, there might be a high risk of surface and groundwater contamination along with the great chance to enter the heavy metals to the food chain through the bio-accumulation. It is therefore essential to take immediate measure to minimize the soil and water pollution around the environment at both landfill sites. Solid waste solidification/stabilization is a popular technology used in many developed countries to save the environment from the heavy metal pollution by immobilizing the heavy metals within the solidified matrix bond. In Bangladesh, there might be a great scope in reusing the landfill decomposed solid waste as construction material after proper solidification /stabilization.

\section{Acknowledgements}

The Authors wish to acknowledge the authority of Dhaka South and North City Corporations for the research grant to carry out this study at Matuail and Aminbazar dumping sites.

\section{RFERENCES}

[1] DCC, 2011. Annual Activities Report on Solid Waste Management, from July to June in the year 2010/2011. Project for Strengthening of Solid Waste Management in Dhaka City.

[2] Mor, S; Ravindra, K ; Dahiyaa,R.P., Chandra, A, (2006), "Leachate Characterization and assessment of groundwater pollution near municipal solid waste landfill site,’[online].Availableat:https://uhra.herts.ac.uk/dspace/bitst ream/2299/2039/1/902166.pdf [Accessed 16th August 2012].

[3] Haque, M. A., Hoque, M. A., Modal, M. S. A., Rahman, M. T., (2013), "Characterization of Leachate and Solid Waste of 
Dhaka City Corporation Landfill Site for Solid Waste Stabilization", American Journal of Civil Engineering and Architecture, 1(2): 39-42.

[4] Ukpong, E. C., Antigha, R. E., Moses, E. O. (2013), "Assessment of Heavy Metals Content In Soils And Plants Around Waste Dumpsites In Uyo Metropolis, Akwa Ibom State", The International Journal Of Engineering And Science, 2(7): 75-86.

[5] Yahaya, M. I., Mohammad, S., Abdullahi, B. K. (2009), "Seasonal Variations of Heavy Metals Concentration in Abattoir Dumping Site Soil in Nigeria," J. Appl. Sci.Environ.Manage,13(4):9 - 13.

[6] Mamtaz, R., Chowdhury,M. H., (2006). "Leaching characteristics of solid waste at an urban solid waste dumping site" Journal of Civil Engineering (IEB), 34(2):71-79.

[7] Oluyemi, E. A. , Feujit, G., Oyekunle, J.A.O. and Ogunfowokan, A.O. (2008) 'Seasonal variations in heavy metal concentrations in soil and some selected crops at a landfill in Nigeria', African Journal of EnvironmentalScience and Technology, 2 (5):89-96.

[8] Adjia, R., Fezeu, W. M. L., Tchatchueng, J. B Sorho,S.,Echevarria, G.,Ngassoum, M. B., (2008), "Long term effect of municipal solid waste amendment on soil heavy metal content of sites used for periurban agriculture in Ngaoundere,"Cameroon', African Journal of Environmental Science and Technology, 2 (12):412-421.

[9] BECR,1997. Bangladesh Environmental Conservation Rules1997.[online].Availabeat:http://www.doe-bd.org/2nd_p art/179-226.pdf [Accessed 28th August 2012].

[10] Ryskamp, DA (2010), The effect of soil pollution on humans,[Online].Availbleat:http://www.livestrong.com /article/176005-the-effects-of-soil-pollution-on-humans/ [Accessed 26th August 2012].

[11] Aljaradin, M., Persson, K. M., (2012), 'Environmental Impact of Municipal Solid Waste Landfills in Semi-Arid Climates - Case Study - Jordan', The Open Waste Management Journal, 5:28-39. 